

\title{
Soiling of building envelope surfaces and its effect on solar reflectance - Part III: Interlaboratory study of an accelerated aging method for roofing materials
}

\author{
Mohamad Sleiman $^{\mathrm{a}, \mathrm{b}, \mathrm{c}}$, Sharon Chen ${ }^{\mathrm{a}}$, Haley E. Gilbert ${ }^{\mathrm{a}}$, Thomas W. Kirchstetter ${ }^{\mathrm{a}, \mathrm{d}}$, \\ Paul Berdahl ${ }^{\mathrm{a}}$, Erica Bibian ${ }^{\mathrm{e}}$, Laura S. Bruckman ${ }^{\mathrm{f}, \mathrm{g}}$, Dominic Cremona ${ }^{\mathrm{h}}$, \\ Roger H. French ${ }^{\text {f,g,i,j, Devin A. Gordon }}{ }^{\mathrm{f}, \mathrm{i}}$, Marco Emiliani ${ }^{\mathrm{k}}$, Justin Kable ${ }^{\mathrm{e}}$, Liyan Ma ${ }^{1}$, \\ Milena Martarelli ${ }^{\mathrm{m}}$, Riccardo Paolini ${ }^{\mathrm{n}}$, Matthew Prestia ${ }^{\mathrm{o}}, \mathrm{J}_{\mathrm{ohn}}$ Renowden ${ }^{\mathrm{e}}$, \\ Gian Marco Revel ${ }^{\mathrm{p}}$, Olivier Rosseler ${ }^{\mathrm{q}}$, Ming Shiao, Giancarlo Terraneo ${ }^{\mathrm{r}, \mathrm{s}}$, Tammy Yang ${ }^{\mathrm{o}}$, \\ Lingtao $\mathrm{Yu}^{\mathrm{o}}$, Michele Zinzi ${ }^{\mathrm{t}}$, Hashem Akbari ${ }^{\mathrm{u}}$, Ronnen Levinson ${ }^{\mathrm{a}}$, Hugo Destaillats ${ }^{\mathrm{a}, *}$ \\ *Corresponding author's E-mail: HDestaillats@LBL.gov \\ Submitted to Solar Energy Materials and Solar Cells
}

\footnotetext{
${ }^{a}$ Heat Island Group, Environmental Energy Technologies Division, Lawrence Berkeley National Laboratory, Berkeley, CA, USA

${ }^{b}$ Clermont Université, ENSCCF, Institut de Chimie de Clermont-Ferrand, BP 10448, F-63000 ClermontFerrand, France

${ }^{c}$ CNRS, UMR 6296, ICCF, BP 80026, F-63177 Aubière, France

${ }^{d}$ Department of Civil and Environmental Engineering, University of California Berkeley, Berkeley, CA, USA

e Boral Roofing LLC, Irvine, CA, USA

${ }^{f}$ Solar Durability and Lifetime Extension Center, Case Western Reserve University, Cleveland, OH, USA

${ }^{\mathrm{g}}$ Material Science and Engineering Department, Case Western Reserve University, Cleveland, OH, USA

${ }^{\mathrm{h}}$ Tremco Roofing \& Building Maintenance, Beachwood, OH, USA

'Macromolecular Science and Engineering Dept., Case Western Reserve University, Cleveland, OH, USA

${ }^{j}$ Physics Department, Case Western Reserve University, Cleveland, OH, USA

${ }^{k}$ Department of Industrial Engineering and Mathematical Sciences, Università Politecnica delle Marche, Ancona, Italy

'CertainTeed, Malvern, PA, USA

${ }^{m}$ Università degli studi e-Campus, Novedrate (CO), Italy

${ }^{n}$ Department of Department of Architecture, Built environment and Construction engineering, Politecnico de Milano, Milan, Italy

${ }^{\circ}$ GAF Materials Corporation, Wayne, NJ, USA

${ }^{\mathrm{p}}$ Department of Industrial Engineering and Mathematical Sciences, Università Politecnica delle Marche, Ancona, Italy

${ }^{\mathrm{q}}$ Saint Gobain Research Center, Northborough, MA, USA

'Department of Chemistry, Materials, and Chemical Engineering "Giulio Natta", Politecnico di Milano, Milan, Italy

${ }^{5}$ FluorlT, via Varese 25/D, 21047 Saronno (VA), Italy

${ }^{t}$ ENEA-UTEE-ERT Italian National Agency for New Technologies, Energy and Sustainable Economic Development, Rome, Italy

${ }^{u}$ Concordia University, Department of Building, Civil and Environmental Engineering, Montreal, Canada
} 


\begin{abstract}
A laboratory method to simulate natural exposure of roofing materials has been reported previously (Sleiman et al, Sol. Energy Mater. Sol. Cells 2014, 122, 271-281). In this article, we describe the results of an international, nine-participant interlaboratory study (ILS) conducted in accordance with ASTM Method E691-09 to establish the precision and reproducibility of this protocol. The accelerated soiling and weathering method was applied four times by each laboratory to duplicate coupons of 12 products representing a wide variety of roofing categories (single-ply membrane, field-applied coating, factoryapplied coating, shingle, modified bitumen, clay tile, and concrete tile). Participants reported initial and laboratory-aged values of solar reflectance and thermal emittance. Measured solar reflectances were consistent within and across eight of the nine participating laboratories. Measured thermal emittances reported by six participants exhibited comparable consistency. For solar reflectance, the accelerated aging method is both repeatable and reproducible within an acceptable range of standard deviations: the repeatability standard deviation $s_{r}$ ranged from 0.008 to 0.015 (relative standard deviation of $1.2-2.1 \%$ ) and the reproducibility standard deviation $s_{R}$ ranged from 0.022 to 0.036 (relative standard deviation of $3.2-5.8 \%$ ). The ILS confirmed that the accelerated aging method can be reproduced by multiple independent laboratories with acceptable precision. This study supports the adoption of the accelerated aging practice to speed the evaluation and performance rating of new cool roofing materials.
\end{abstract}




\section{Introduction}

Highly reflective roofs can decrease the energy required for building air conditioning, help mitigate the urban heat island effect, and slow global warming [1-6]. However, these benefits are diminished by soiling and weathering processes that reduce the solar reflectance of most roofing materials [7-11]. Soiling results from the deposition of atmospheric particulate matter and the growth of microorganisms, both of which absorb sunlight. Weathering of materials occurs with exposure to water, sunlight, and temperature change [9].

This article describes an interlaboratory study (ILS) conducted to establish the precision and reproducibility of an accelerated aging method, developed by Lawrence Berkeley National Laboratory (LBNL), that mimics the changes to the solar reflectance and thermal emittance of roofing materials induced by natural exposure. It follows recent publication of two studies that (a) analyzed the initial and aged radiative properties of hundreds of products rated by the Cool Roof Rating Council (CRRC) and the Energy Star program of the U.S. Environmental Protection Agency (EPA) [8]; and (b) developed an accelerated aging method to simulate in the laboratory weathering and soiling processes in a much shorter time frame [7].

The accelerated aging method consists of three steps: (1) exposing a roofing product in a weathering apparatus before soiling, to provide UVA, moisture and temperature conditioning; (2) spraying a waterborne soiling mixture that includes soot, organic matter, dusts, and salts; and (3) exposing the soiled coupon in the weathering apparatus to simulate the cleaning effect of condensation runoff. The method was applied to 26 products - single ply membranes, factory applied coatings (on metal), field applied coatings, clay tiles, concrete tiles, modified bitumen cap sheets, and asphalt shinglesand shown to reproduce in three days the CRRC's three-year aged values of solar reflectance [7]. This practice was approved in March 2015 by ASTM International as D7897-15, "Standard Practice for Laboratory Soiling and Weathering of Roofing Materials to Simulate Effects of Natural Exposure on Solar Reflectance and Thermal Emittance" [12]. In April 2015, ASTM D7897-15 was adopted by the CRRC as an option 
for obtaining interim "aged" ratings for roofing products while they undergo three years of natural exposure [13].

We found that the use of ASTM methods for the interlaboratory study was effective and based on considerable experience in prior similar studies. On the other hand, the details of the methods are complex. Repeated measurements, subject to some error, are assumed to follow normal (i.e., Gaussian) distributions. Results of the various laboratories are also assumed to follow normal distributions. If a large number of measurements can be made it is a simple matter to compute the mean and standard deviation of the distribution, which completely determines the underlying distribution. However, the availability of only a few measurements inherently involves the statistics of small groups of numbers. For example, if we have only five samples from a distribution, how accurately can we estimate even the mean? As is well known, drawing inferences from limited data sets must be done with care. Therefore we followed the established ASTM methods.

The results of the ILS, as well as feedback from the participating laboratories, are reported. A precision statement that includes the repeatability and reproducibility determined in this ILS was developed for incorporation into the ASTM draft standard. The adoption of the accelerated aging method as an ASTM practice should provide a useful tool for the roofing and weathering industry to speed prototyping and development of high performance building envelope materials that resist soiling, maintain high solar reflectance, and save energy.

\section{Theory}

The ILS was designed and executed in accordance with ASTM E691-09, "Standard Practice for Conducting an Interlaboratory Study to Determine the Precision of a Test Method" [14], which is substantively similar to the current version of this standard, ASTM E691-14 [15]. The ILS was led by LBNL. Data from the interlaboratory study were used to evaluate the method's consistency, and to estimate precision statistics (within-lab and between-lab variations). 
Evaluation of consistency for measurements made on a given specimen-here, a roofing product - involve two statistics, $k$ (within-laboratory) and $h$ (between-laboratories). Let a 'cell' denote the set of $n$ replicate measurements performed by one of $p$ participants, and $x_{i, j}$ represent the value for replicate $j$ measured by participant $i$. The within-laboratory consistency statistic $k$ for participant $i$ is the ratio of the cell standard deviation for participant $i, s_{i}$, to the repeatability standard deviation, $s_{r}[15]$. That is,

$$
k_{i} \equiv \frac{s_{i}}{s_{r}},
$$

where

$$
s_{i} \equiv \sqrt{\frac{\sum_{j=1}^{n}\left(x_{i, j}-\bar{x}_{i}\right)^{2}}{n-1}}
$$

and

$$
s_{r} \equiv \sqrt{\frac{\sum_{i=1}^{p}\left(s_{i}\right)^{2}}{p}} .
$$

Here

$$
\bar{x}_{i} \equiv \frac{\sum_{j=1}^{n} x_{i, j}}{n}
$$

is the cell average for participant $i$. The $k$ statistic compares variability within a laboratory to variability over all laboratories.

The between-laboratories consistency statistic $h$ for participant $i$ is the ratio of the cell deviation for participant $i$ to the standard deviation of the cell averages for all participants. That is,

$$
h_{i} \equiv \frac{\bar{x}_{i}-\overline{\bar{x}}}{s_{\bar{x}}}
$$

where

$$
\overline{\bar{x}} \equiv \frac{\sum_{i=1}^{p} \bar{x}_{i}}{p}
$$

is the average of the cell averages, and 


$$
s_{\bar{x}} \equiv \sqrt{\frac{\sum_{i=1}^{p}\left(\bar{x}_{i}-\overline{\bar{x}}\right)^{2}}{p-1}}
$$

is the standard deviation of the cell averages. The $h$ statistic can be used to evaluate the overall variability of the measurements among the participants, and to compare the results of one participant to those of all other participants.

According to ASTM E691-14, critical values of $k$ and $h$ are used to identify inconsistent results. When the $k$ or $h$ statistic for a given laboratory and specimen exceeds its critical value, the deviation is considered to exceed the expected fluctuations due to random error, and thus warrants investigation. If the investigation reveals no clerical, sampling, or procedural errors, the unusual data are retained. However, if a laboratory deviated significantly from the test protocol, the test results for that laboratory should be removed from the calculation of the precision statistics.

The equations for $k_{\text {critical }}$ and $h_{\text {critical }}$ are derived in Appendices X1.2.2 and X1.2.3 of ASTM E691-14, and their values are given in Table 5 of that standard. For an ILS with nine participants $(p=9)$, four replicates $(n=4)$, and a significance level of $0.5 \%, k_{\text {critical }}$ is 1.92 and $h_{\text {critical }}$ is 2.23 . If the number of participants is reduced to eight, $k_{\text {critical }}$ is 1.90 and $h_{\text {critical }}$ is 2.15 . With only six participants, $k_{\text {critical }}$ is 1.84 and $h_{\text {critical }}$ is 1.92 . The choice of the significance level of $0.5 \%$ is based on experience in prior interlaboratory studies [14], as a compromise to flag suspicious data while limiting false positive alarms.

Once data consistency has been verified, and action has been taken to remove inconsistent results, the consistency statistcs were recalculated and the precision statistics were determined. The precision assesses the variability one may expect when the test method is used by one or more laboratories, and is defined in ASTM E691-14 as "the closenesss of agreement among test results obtained under prescribed conditions." The method precision was evaluated by calculating the repeatability and reproducibility statistics according to ASTM E691-14, in which: 
- "repeatability concerns the variability between independent test results obtained with the same method on identical test specimens in the same laboratory by the same operator using the same equipment within short intervals of time"; and

- "reproducibility deals with the variability between single test results obtained in different laboratories, each of which has applied the test method to test specimens".

To assess repeatability and reproducibility, two expressions were used: the estimated $95 \%$ repeatability limit, $r$; and the estimated $95 \%$ reproducibility limit, $R$. A nonstatistical interpretation of these values is that these are the maximum difference between two test results obtained under specified conditions that can be attributed to the test method precision. Hence, $r$ and $R$ can be used as decision limits to support or challenge the validity of the assumption that both test results have been produced on the same material in a correct manner under the associated specific conditions. The $r$ and $R$ parameters were calculated in accordance with ASTM E691-14, Section 21.1, as follows:

$$
r=2.8 s_{r}
$$

and

$$
R=2.8 s_{R}
$$

where

$$
s_{R}=\sqrt{\left(s_{\bar{x}}\right)^{2}+\left(s_{r}\right)^{2}(n-1) / n}
$$

is the reproducibility standard deviation.

\section{Experiment}

The interlaboratory study involved performing the accelerated aging method by nine different laboratories using a set of 12 roofing products, according to an experimental protocol developed by LBNL and detailed in the Electronic Supplementary Material (ESM). The experimental protocol describes the preparation of the soiling mixture, 
calibration of soiling process, recommended equipment, and instructions for measurements and reporting. The measured values of solar reflectance, thermal emittance and standard deviations obtained by each participant were then sent to LBNL for analysis. LBNL conducted the statistical analysis of reported data according to ASTM E691-14 to assess the method's consistency statistics, repeatability, and reproducibility.

\subsection{Roofing products}

The ILS used 12 roofing products representative of the U.S. roofing market. The characteristics of these products are described in Table 1. In addition, two reference products (each bare zincalume steel) were included for calibrating the soiling deposition rate. Four duplicate $10 \mathrm{~cm} \times 10 \mathrm{~cm}$ coupons of each roofing product were sent to each participating laboratory. Each coupon was packed individually in a glassine envelope, and well padded, to prevent contamination and damage during travel and storage.

\subsection{Laboratories}

Section 9.1.2 of ASTM E691-14 recommends a minimum of six laboratories for the development of a precision statement. In this study, a total of nine laboratories participated, including LBNL, three universities (one from the U.S. and two from Italy), and five roofing manufacturers (Table 2). Each participant measured and reported solar reflectance. Only six of the nine participants reported thermal emittance, because three lacked the equipment needed to measure this property.

\subsection{Instrumentation}

A detailed list of recommended equipment needed to perform the accelerated aging test was prepared and sent to all participating laboratories prior to the start of the ILS. The equipment included:

a. Weathering device: an apparatus that exposes roofing materials to alternating cycles of ultraviolet (UVA) light and moisture at controlled, elevated temperatures $[16,17]$. 
b. Soiling apparatus: an air-pressurized spraying tank, equipped with an air pressure gauge and connected to a hollow-cone fine spraying nozzle [7].

c. Solar spectrum reflectometer: a portable solar reflectometer (e.g., Devices \& Services Solar Spectrum Reflectometer model SSR-E) to measure the solar reflectance of opaque materials in accordance with ASTM Standard C1549-09 [18].

d. Thermal emissometer: a thermal emissometer with scaling digital voltmeter (e.g., Devices \& Services model AE1 RD1) to measure the thermal emittance in accordance with ASTM C1371-04a [19].

e. Solar spectrophotometer (optional): a solar (UV-Vis-NIR) spectophotometer (e.g., Perkin-Elmer Lambda 950) with integrating sphere to measure solar spectral reflectance in accordance with ASTM E903-12 [20].

The soiling apparatus is detailed in a companion article [7]. A description and pictures of the LBNL soiling apparatus were also included in the test protocol sent to the participants to provide sufficient detail for assembly and operation (ESM Figures S2 and S3). After assembly of the soiling apparatus, all laboratories were instructed to follow the calibration process detailed in the test protocol (see ESM).

\subsection{Chemicals and soiling mixture}

The soiling mixture incorporates the following four agents in water:

a. Soot: A commercially available self-dispersible carbon black (Aquablack 001; Tokai Ltd).

b. Dust: A mixture of iron oxide $\left(\mathrm{Fe}_{2} \mathrm{O}_{3}\right)$ powder (color: red-brown, particle size < $5 \mu \mathrm{m}$, purity $\geq 99 \%$, CAS: 1309-37-1) and two natural clays [Montmorillonite K10 powder (color: yellowish-grey, surface area: 220-270 m²/g, CAS: 1318-93-0) and Nanoclay, hydrophilic bentonite (particle size $\leq 25 \mu \mathrm{m}$, CAS: 1302-78-9)]. 
c. Salts: A mixture of sodium chloride ( $\mathrm{NaCl}$, CAS: 7647-14-5), sodium nitrate ( $\mathrm{NaNO}_{3}$, CAS: $\left.7632-00-0\right)$ and calcium sulfate dihydrate $\left(\mathrm{CaSO}_{4} \cdot 2 \mathrm{H}_{2} \mathrm{O}\right.$, CAS: 7778-18-9).

d. Organics: Humic acid (CAS: 1415-93-6), as a surrogate for particulate organic matter and dead microbial colonies.

An image of the individual suspensions of soiling agents was provided in the test protocol (ESM Figure S1). The soiling mixture was prepared by combining the four soiling agents described above to obtain the following final concentrations in the mixture: $0.575 \mathrm{~g} / \mathrm{L}$ dust, $0.25 \mathrm{~g} / \mathrm{L}$ salts, $0.35 \mathrm{~g} / \mathrm{L}$ humic acid, and $0.0625 \mathrm{~g} / \mathrm{L}$ carbon black in the soiling mixture (see ESM).

\subsection{Test protocol}

A test protocol was developed by LBNL and shared with all participating laboratories prior to the conduct of the ILS. The protocol is summarized in this section, and fully detailed in the ESM.

\subsubsection{Measurements}

The solar reflectance and thermal emittance of each specimen was measured first upon receipt of all specimens, and again after conducting the accelerated aging practice. For solar reflectance measurements, participants were instructed to use a Devices \& Services Solar Spectrum Reflectometer (SSR) following ASTM Standard C1549-09, using outputs "1.5" (SSR version 5) or outputs "1.5E" and "G1" (SSR version 6) [18]. The "1.5" (SSR version 5) or "1.5E" (SSR version 6) solar reflectance output was used in the consistency analysis because this metric is currently used in the CRRC Product Rating Program [13]. For specimens with a smooth surface, two measurements per specimen were recorded. For specimens with rough surface (e.g., granule-surfaced shingles or modified bitumen), three measurements per specimen were recorded. 
Thermal emittance was measured using a portable emissometer (Devices \& Services Model AE1) following ASTM C1371-04a(2010)e1 [19], as specified in the CRRC Product Rating Program CRRC- ${ }^{\phi}[13,21]$.

\subsubsection{Accelerated aging}

The accelerated aging method consists of three steps:

Step 1. Conditioning: Each specimen is exposed in a weathering apparatus to $24 \mathrm{~h}$ of cycle 1 of ASTM G154-12a, "Standard Practice for Operating Fluorescent Ultraviolet (UV) Lamp Apparatus for Exposure of Nonmetallic Materials" [22]. After conditioning, the specimen is dried at room temperature for about $2 \mathrm{~h}$.

Step 2. Soiling: The conditioned specimen is soiled using the apparatus and mixture described above in Sections 3.3 and 3.4, respectively, and then dried under an infrared lamp. To ensure proper application of the soiling mixture, the soiling apparatus is calibrated with a reference specimen as described in the test protocol (see ESM).

Step 3. Weathering: The soiled and dried roofing specimen is exposed in the weathering apparatus to $24 \mathrm{~h}$ of cycle 1 of ASTM G154-12a.

\subsubsection{Reporting}

Participating laboratories were instructed to report the values of solar reflectance for all tested specimens and the standard deviations of replicate measurements (ESM Table S2). Those with equipment to measure thermal emittance were also asked to report that property.

\footnotetext{
$\phi$ In November 2011, the CRRC-1 Product Rating Program was updated to require the use of a "slide method" when using the portable emissometer to measure the thermal emittance of nonmetal products. However, the reported values of aged thermal emittance in the CRRC's Rated Product Directory being used for validation were made following ASTM C1371, without the slide method.
} 


\section{Results and discussion}

\subsection{Solar reflectance consistency}

Examination of Figure 1a shows that the $k$ statistics for eight of the nine participants (Labs $\mathrm{A}-\mathrm{H}$ ) were below $k_{\text {critical }}=1.92$ for all 12 roofing products tested. The higher $k$ statistics for products 3 (asphalt shingle) and 4 (clay tile) are likely due to the low initial solar reflectance of those products, which led to smaller changes after accelerated aging and thus higher standard deviations.

As for Lab I, the $k$ statistic reported exceeded $k_{\text {critical }}$ for 10 of the 12 products. This finding means that the variation of results for Lab I is inconsistent with (higher than) that for the other participants. It also indicates intralaboratory imprecision, which may be related to procedural differences.

An investigation by LBNL and Lab I concluded that the primary cause of these inconsistent results was improper deposition of the soiling mixture, leading to a nonuniform soiling pattern and wet soiling masses that deviated significantly from the range recommended by the test protocol. The results from Lab I were then removed and the $k$ statistics were recalculated and shown in Figure 1B. In addition, based on recommendation and feedback from Lab I and other participants, the following corrective actions and editorial changes were incorporated into the ASTM draft.

- The revised draft specifies that: "after soiling and drying, the surface of the reference specimen should appear to be covered with evenly separated and randomly distributed soil spots with diameters ranging between $1.5 \mathrm{~mm}$ and 3.0 mm".

- The revised draft specifies that "the uniformity of the soiling on the dried specimen shall be assessed visually. If the specimen is not uniformly soiled, the calibration process shall be repeated on unexposed reference specimens until uniform soiling is attained". Furthermore, the report shall include "photographs of the specimen before and after simulated field exposure." 
- The revised draft recommends agitation of the soiling mixture: "the soiling mixture is agitated for $1-2$ minutes to re-suspend any settled particles, then placed into the spraying vessel. The soiling mixture shall be re-agitated hourly if the calibration process takes more than 1 hour."

- The revised draft specifies that "dry surface coverage (expressed in $\mathrm{mg} / \mathrm{cm}^{2}$ ) should be reported instead of wet soiling mass retention (expressed in $\mathrm{g}$ )".

- The revised draft specifies that "calibration should be repeated at least two times, to verify that the wet soiling mass retained by the $10 \mathrm{~cm} \times 10 \mathrm{~cm}$ reference specimen does not differ from $0.8 \mathrm{~g}$ by more than 0.1 (dry surface coverage of $8 \pm$ $1 \mathrm{mg} / \mathrm{cm}^{2}$ ) and that the soiling pattern is uniform. If the wet soiling mass deposited on the reference specimen is less than $0.7 \mathrm{~g}\left(7 \mathrm{mg} / \mathrm{cm}^{2}\right)$, the spraying time should be increased. If the wet soiling mass is greater than $0.9 \mathrm{~g}\left(9 \mathrm{mg} / \mathrm{cm}^{2}\right)$, the spraying time should be decreased".

Despite the presence of an outlier (laboratory I), the $k$ statistics of laboratories A-H fell well below $k_{\text {critical, }}$ with an average $k$ statistic of 0.89 for all products tested (compared with $k_{\text {critical }}=1.90$ for eight laboratories). Only four $k$ statistics out of the 96 values were close to the $\mathrm{k}_{\text {critical }}$ caused by an inconsistent aged solar reflectance value for one of the four specimens tested. However, no systematic bias or error was found for any of the products tested or the partipating laboratories, since most $k$ statistics were reasonably below $\mathrm{k}_{\text {critical }}$. After excluding results from Lab I, the eight remaining laboratories yielded an intralaboratory consistency parameter $k<k_{\text {critical }}=1.90$ for all but one of 96 measurements (Figure 1b).

The $h$ statistics for the results of the nine independent laboratories are plotted in Figure 2a. Inspection of Figure 2 indicates a strong consistency for variation among laboratories A-H. Only Lab I stands out with $h$ statistics that exceed $h_{\text {critical }}(|\mathrm{h}|>2.23)$ for 11 out of the 12 products tested. Most $h$ statistics for laboratories $\mathrm{A}-\mathrm{H}$ are positive, indicating that they are biased systematically in the same direction. This bias is not due to procedural error but can be attributed to the reduction in $\overline{\bar{x}}$ resulting from low solar reflectance values reported by Lab I. By removing Laboratory I data, $h$ statistics are well distributed 
between negative and positive values for all labs indicating the absence of systematic bias as shown in Figure $2 \mathrm{~b}$. The eight remaining laboratories yielded an interlaboratory consistency parameter $|h|<\left|h_{\text {critical }}\right|=2.15$ for all measurements.

\subsection{Thermal emittance consistency}

An analogous statistical analysis was performed to evaluate the consistency of thermal emittance values reported by six of the nine participating laboratories (Labs B-G). The results of the analysis illustrated in Figures 3 and 4 indicate very good consistency within-laboratory and between-laboratories as indicated by the absence of systematic bias or outliers. Overall, only four out of $72 k$ statistics exceeded $k_{\text {critical }}$ (1.84), while only one $h$ statistic exceeded $h_{\text {critical }}(|\mathrm{h}|>1.92)$. Moreover, the $h$ values for all laboratories exhibit a random pattern that suggest no systematic bias.

Given the observed small changes in thermal emittance caused by the accelerated aging, these outliers are likely the result of measurement bias rather than an error due to the soiling and weathering processes. This is supported by the absence of similar bias in the solar reflectance data for the same specimens. These outliers represent only a very small fraction of the ILS data reported (1 out of $72 h$ statistics and 4 out of $72 k$ statistics) and thus their contribution to the precision statistics is very limited. Since these errors cannot be explained by procedural errors or deviation from the test protocol, they were retained for the estimation of the precision statistics as recommended by ASTM E691-14.

\subsection{Precision statistics}

The calculated values of $s_{r}, s_{R}, r$ and $R$ for solar reflectance measurements are summarized by product in Table 3. Thus, for example, the repeatability and reproducibility limits for Product 1 were computed to be $r=0.022$ and $R=0.061$, respectively. This suggests that for Product 1, 95\% of all aged solar reflectance values tested within a given laboratory can be expected to differ in absolute value by less than $0.022(3.3 \%)$, while $95 \%$ of all results from laboratories similar to those that participated in this study can be expected to differ in absolute value by less than $0.061(9.2 \%)$. For the set of 12 products, the ranges of repeatability $r$ and reproducibility $R$ were 


$$
\begin{aligned}
& \circ \quad r: 0.018-0.053(\text { mean } 0.032) \\
& \circ \quad R: 0.042-0.098(\text { mean } 0.076)
\end{aligned}
$$

For the set of 12 products, the ranges of relative repeatability $\hat{r}$ (ratio of repeatability $r$ to product mean aged solar reflectance) and relative reproducibility $\hat{R}$ (ratio of reproducibility $R$ to product mean aged solar reflectance) were

$$
\begin{aligned}
& \circ \hat{r}: 2.8-7.9 \%(\text { mean: } 5.4 \%) \\
& \circ \hat{R}: 9.1-19.6 \%(\text { mean: } 12.9 \%)
\end{aligned}
$$

The values of $r$ obtained in the ILS are comparable to the value calculated during previous validation of the method by LBNL, which was about 0.02 [7]. As for $R$, a commonly used rule-of-thumb for interlaboratory studies is that the inter-laboratory reproducibility $R$ should be about twice the intra-laboratory repeatability $r$ [23], which is the case for the results of this ILS. Satisfactorily meeting this rule-of-thumb is an indication of "robustness" of the method, or the absence of large deviations due to changes in operator and/or experimental conditions.

The ranges of $r$ and $R$ appear to be comparable for all six roofing categories tested in the ILS, suggesting that the precision of the method does not depend strongly on type of roofing product. Furthermore, we found that neither $s_{r}$ nor $s_{R}$ correlated with the aged solar reflectance, as seen in Figure 5, indicating that the precision does not depend on solar reflectance. Thus, it is reasonable to consider the mean values of $r$ and $R$ as valid precision metrics.

We also note that the values of $r(0.018$ to 0.053$)$ and $R(0.042-0.098)$ for these solar reflectance measurements exceed by an order of magnitude those of the ASTM C1549 solar reflectance measurement method $(r=0.0017-0.0059 ; \mathrm{R}=0.0043-0.02)$ [18].

Following the same statistical analysis described in Section 2, we estimated $s_{r}, s_{R}, r$ and $R$ for the reported values of thermal emittance (Table 4), and found that for the set of 12 products, the ranges of absolute and relative repeatabilities and reproducibilities were 


$$
\begin{aligned}
& \circ \quad r: 0.017-0.059(\text { mean } 0.036) ; \hat{r}: 1.9-7.3 \%(\text { mean } 4.5 \%) \\
& \circ \quad R: 0.030-0.139(\text { mean } 0.057) ; \hat{R}: 3.5-15.6 \%(\text { mean } 6.8 \%)
\end{aligned}
$$

These numbers are comparable to those obtained for aged solar reflectance. However, as described in the method's validation study [7], the change in thermal emittance caused by either long term outdoor exposure or accelerated aging for most roofing products except bare metal is small $(<0.05)$. Since only one tested product was bare metal, and given that only six laboratories (the minimum number required for an ILS) have reported thermal emittance values, it is difficult to generalize these statistics. The standard deviations of $s_{r}$ and $s_{R}$ as a function of thermal emittance are shown in Figure 6.

We do not compare the repeatability and reproducibility values for these thermal emittance measurements with those reported for the ASTM C1371 thermal emittance measurement method, because the C1371 precision and bias statement was developed only for uninsulated metals [19]. (Only two of the 12 tested products in our study were uninsulated metals.)

When applied to other roofing products, all provisions described here (and listed in ASTM Standard D7897-15) should be followed in order to achieve results with the same precision as those shown in this study.

\subsection{Observations about agitation of soiling mixture}

One laboratory that used sonic agitation (rather than shaking) to disperse the agents in the soiling mixture found that it avoided clogging of the spray nozzle. However, this agitation technique increased the flow rate, making it difficult to regulate wet mass deposition. It also increased the hydrophilicity of the soot, causing the wet mass to move about when the soiled sample was extracted from the soiling chamber. Therefore, sonic agitation of the soiling mixture is not recommended. The soiling mixture should instead be shaken by hand, as stated in the protocol. 


\section{Summary}

An interlaboratory study was conducted to establish the precision of LBNL's accelerated aging method for roofing materials. Analysis of the data according to ASTM E691-14 revealed good consistency of results for eight of the nine participating laboratories. The potential major source of bias for the outlier laboratory was identified as the nonuniformity of the soiling spray application. Upon discussion with all ILS participants, a set of language clarifications and improvements of the ILS protocol was adopted and implemented in the revised version of the ASTM draft recently approved as Standard D7897-15 [12]. These include (i) visual inspection of the soiled specimen, which should be covered with evenly separated and randomly distributed soil spots; (ii) inclusion of a photograph of the aged specimen to verify uniformity of soiling; (iii) a recommendation to agitate the soiling mixture before spraying to well disperse the soiling agents within the mixture tank; and (iv) specification of dry surface coverage (expressed in $\mathrm{mg} / \mathrm{cm}^{2}$ ) instead of wet soiling mass retention (expressed in $\mathrm{g}$ ). Despite the presence of these minor weaknesses in the ILS test protocol, the precision statistics showed that the accelerated aging method is both repeatable and reproducible within an acceptable range of standard deviations for aged solar reflectance and aged thermal emittance:

Precision statement for aged solar reflectance, based on eight participants:

\begin{tabular}{lcc} 
Solar Reflectance & Mean & Range \\
Repeatability $(\boldsymbol{r})$ & 0.032 & $0.018-0.053$ \\
Standard deviation $\left(\boldsymbol{s}_{\boldsymbol{r}}\right)$ & 0.012 & $0.007-0.019$ \\
\hline Reproducibility $(\boldsymbol{R})$ & 0.076 & $0.042-0.098$ \\
Standard deviation $\left(\boldsymbol{s}_{\boldsymbol{R}}\right)$ & 0.028 & $0.015-0.036$ \\
\hline
\end{tabular}

Precision statement for aged thermal emittance, based on six participants: 


\begin{tabular}{lcc} 
Thermal Emittance & Mean & Range \\
\hline Repeatability $(\boldsymbol{r})$ & 0.036 & $0.017-0.059$ \\
Standard deviation $\left(\boldsymbol{s}_{\boldsymbol{r}}\right)$ & 0.012 & $0.006-0.021$ \\
\hline Reproducibility $(\boldsymbol{R})$ & 0.052 & $0.030-0.139$ \\
Standard deviation $\left(\boldsymbol{s}_{\boldsymbol{R}}\right)$ & 0.019 & $0.011-0.050$ \\
\hline
\end{tabular}

It is also important to highlight that due to time constraints, these precision statistics were obtained without training the ILS participants and without pilot runs. It is thus possible that the precision could be better as a result of (a) improvements in the test protocol and (b) increasing familiarity and proficiency by future adopters of this method.

This study provides additional validation and evidence that the accelerated aging method is practical, robust and reproducible. It constitutes an important step towards the establishment of an ASTM standard practice for simulating field exposure of roofing materials. Once adopted by ASTM, this practice should help the roofing and weathering industries speed prototyping and the development of high performance roofing materials that resist soiling, maintain high solar reflectance, and save energy.

\section{Acknowledgements}

This work was supported by the Assistant Secretary for Energy Efficiency and Renewable Energy, Building Technologies Office of the U.S. Department of Energy under Contract No. DE-AC02-05CH11231. The authors thank Marc LaFrance, Alexis Abramson, Karma Sawyer, and Patrick Phelan of the Department of Energy (Office of Energy Efficiency and Renewable Energy, Building Technologies Office) for program management and support. The authors also recognize the significant support from several industrial collaborators, who provided the roofing samples for the interlaboratory testing and contributed invaluable feedback and suggestions to improve the accelerated aging method. M. Emiliani, G.M. Revel and M. Martarelli were supported by the COOLCoverings project (2010-2013), partly funded by EU commission under FP7 (G.A. 260132). R. Paolini, G. Terraneo, and M. Zinzi were supported by the project "Cinque 
per mille junior - Rivestimenti fluorurati avanzati per superfici edilizie ad alte prestazioni”, funded by Agenzia delle Entrate (Italian Revenue Agency) through Politecnico di Milano. We also thank Kurt Sosinski (Tremco Roofing \& Building Maintenance) for his contributions to this project.

\section{References}

1. R. Levinson, H. Akbari, S. Konopacki and S. Bretz. Inclusion of cool roofs in nonresidential Title 24 prescriptive requirements. Energy Policy 33, (2005), 151-170.

2. A.H. Rosenfeld, H. Akbari, J.J. Romm and M. Pomerantz. Cool communities: strategies for heat island mitigation and smog reduction. Energy and Buildings 28, (1998), 51-62.

3. H. Akbari, H.D. Matthews and D. Seto. The long-term effect of increasing the albedo of urban areas. Environ. Res. Letters 7, (2012), 024004.

4. IEA. $\mathrm{CO} 2$ emissions from fuel combustion. Highlights. International Energy Agency OECD/IEA, Paris, France. http://www.iea.org/publications/freepublications/publication/CO2emissionfromfuelcomb ustionHIGHLIGHTSMarch2013.pdf (2012),

5. G.M. Revel, M. Martarelli, M. Emiliani, L. Celotti, R. Nadalini, A. De Ferrari, S. Hermanns and E. Beckers. Cool products for building envelope - Part II: Experimental and numerical evaluation of thermal performances. Solar Energy 105, (2014), 780-791.

6. G.M. Revel, M. Martarelli, M. Emiliani, A. Gozalbo, M.J. Orts, M.A. Bengochea, L.G. Delgado, A. Gaki, A. Katsiapi, M. Taxiarchou, I. Arabatzis, I. Fasaki and S. Hermanns. Cool products for building envelope - Part I: Development and lab scale testing. Solar Energy 105, (2014), 770-779.

7. M. Sleiman, T.W. Kirchstetter, P. Berdahl, H.E. Gilbert, S. Quelen, L. Marlot, C.V. Preble, S. Chen, A. Montalbano, O. Rosseler, H. Akbari, R. Levinson and H. Destaillats. Soiling of building envelope surfaces and its effect on solar reflectance - Part II: Development of an accelerated aging method for roofing materials. Solar Energy Materials and Solar Cells 122, (2014), 271-281.

8. M. Sleiman, G. Ban-Weiss, H.E. Gilbert, D. Francois, P. Berdahl, T.W. Kirchstetter, H. Destaillats and R. Levinson. Soiling of building envelope surfaces and its effect on solar reflectance-Part I: Analysis of roofing product databases. Solar Energy Materials and Solar Cells 95, (2011), 3385-3399.

9. P. Berdahl, H. Akbari, R. Levinson and W.A. Miller. Weathering of roofing materials An overview. Construction and Building Materials 22, (2008), 423-433.

10. G.M. Revel, M. Martarelli, M.A. Bengochea, A. Gozalbo, M.J. Orts, A. Gaki, M. Gregou, M. Taxiarchou, A. Bianchin and M. Emiliani. Nanobased coatings with improved NIR reflecting properties for building envelope materials: Development and natural aging effect measurements. Cement \& Concrete Composites 36, (2013), 128-135. 
11. R. Paolini, M. Zinzi, T. Poli, E. Carnielo and A.G. Mainini. Effect of ageing on solar spectral reflectance of roofing membranes: natural exposure in Roma and Milano and the impact on the energy needs of commercial buildings. . Energy and Buildings 84, (2014), 333-343.

12. ASTM. ASTM D7897-15 Standard Practice for Laboratory Soiling and Weathering of Roofing Materials to Simulate Effects of Natural Exposure on Solar Reflectance and Thermal Emittance. American Society for Testing and Materials, West Conshohocken, PA, 2015. http://www.astm.org/Standards/D7897.htm.

13. CRRC. CRRC Product Rating Program CRRC-1, October. Cool Roof Rating Council, Oakland, CA, 2012.

http://www.coolroofs.org/documents/CRRC-1_Program_Manual_100412.pdf

14. ASTM. ASTM E691-09. Standard Practice for Conducting an Interlaboratory Study to Determine the Precision of a Test Method. American Society for Testing and Materials, West Conshohocken, PA, 2009. http://www.astm.org/DATABASE.CART/HISTORICAL/E691-09.htm.

15. ASTM. ASTM E691-14. Standard practice for conducting an interlaboratory study to determine the precision of a test method. American Society for Testing and Materials, West Conshohocken, PA, 2014. www.astm.org/Standards/E691.htm

16. ASTM. ASTM G151-10 Standard Practice for Exposing Nonmetallic Materials in Accelerated Test Devices that Use Laboratory Light Sources. American Society for Testing and Materials, West Conshohocken, PA, 2010. http://www.astm.org/Standards/G151.htm

17. ASTM. ASTM G154-12a Standard Practice for Operating Fluorescent Ultraviolet (UV) Lamp Apparatus for Exposure of Nonmetallic Materials. American Society for Testing and Materials, West Conshohocken, 2012. http://www.astm.org/Standards/G154.htm.

18. ASTM. ASTM C1549-09: Standard Test Method for Determination of Solar Reflectance Near Ambient Temperature Using a Portable Solar Reflectometer. American Society for Testing and Materials, West Conshohocken, PA, 2009. http://www.astm.org/Standards/C1549.htm

19. ASTM. ASTM C1371-04a(2010)e1: Standard Test Method for Determination of Emittance of Materials Near Room Temperature Using Portable Emissometers. American Society for Testing and Materials, West Conshohocken, PA, 2010. http://www.astm.org/Standards/C1371.htm

20. ASTM. ASTM E903-12. Standard Test Method for Solar Absorptance, Reflectance, and Transmittance of Materials Using Integrating Spheres. American Society for Testing and Materials, West Conshohocken, PA, 2012. http://www.astm.org/Standards/E903.htm.

21. C. Moore. Model AE1 emittance measurements using a port adapter, Model AE-ADP. Technical note 11-2. Devices and Services, Dallas, TX. http://www.devicesandservices.com/TechNotes/TN11-2.pdf (2011), In November 2011, the CRRC-1 Product Rating Program was updated to require the use of a "slide method" when using the portable emissometer to measure the thermal emittance of nonmetal products. However, the reported values of aged thermal emittance in the CRRC's Rated 
Product Directory being used for validation were made following ASTM C1371, without the slide method. .

22. ASTM. ASTM G154-12a. Standard Practice for Operating Fluorescent Ultraviolet (UV) Lamp Apparatus for Exposure of Nonmetallic Materials. American Society for Testing and Materials, West Conshohocken, PA, 2012. http://www.astm.org/Standards/G154.htm

23. A.T. Riga and G.H. Patterson. ASTM, STP 1326. Oxidative Behavior of Materials by Thermal Analytical Techniques (1997). 


\section{Table 1. Description of products used in inter-laboratory tests}

\begin{tabular}{|c|c|c|c|c|c|}
\hline \multirow{2}{*}{$\begin{array}{c}\text { Product } \\
\#\end{array}$} & \multirow{2}{*}{ Product type } & \multirow{2}{*}{ Color } & \multicolumn{2}{|c|}{ Initial Solar Reflectance ${ }^{a}$} & \multirow{2}{*}{$\begin{array}{l}\text { Initial Therma } \\
\text { Emittance }\end{array}$} \\
\hline & & & Output G1 & Output b891 & \\
\hline 1 & factory-applied coating (painted metal) & white & $0.73-0.74$ & $0.76-0.77$ & $0.86-0.87$ \\
\hline 2 & single-ply membrane & white & $0.74-0.75$ & $0.77-0.78$ & $0.85-0.86$ \\
\hline 3 & asphalt shingle & white & $0.26-0.28$ & $0.27-0.29$ & $0.90-0.91$ \\
\hline 4 & clay tile & red & $0.32-0.34$ & $0.36-0.39$ & $0.84-0.85$ \\
\hline 5 & modified bitumen & white & $0.66-0.70$ & $0.69-0.73$ & $0.84-0.85$ \\
\hline 6 & concrete tile & white & $0.80-0.83$ & $0.81-0.84$ & $0.89-0.90$ \\
\hline 7 & field-applied coating & white & $0.81-0.83$ & $0.85-0.87$ & $0.89-0.90$ \\
\hline 8 & bare zincalume steel & metallic grey & $0.67-0.68$ & $0.67-0.68$ & $0.30-0.31$ \\
\hline 9 & field-applied coating & white & $0.81-0.83$ & $0.85-0.87$ & $0.90-0.91$ \\
\hline 10 & single-ply membrane & white & $0.79-0.80$ & $0.82-0.83$ & $0.85-0.86$ \\
\hline 11 & single-ply membrane & white & $0.76-0.78$ & $0.79-0.81$ & $0.85-0.86$ \\
\hline 12 & modified bitumen & white & $0.75-0.80$ & $0.78-0.84$ & $0.85-0.86$ \\
\hline
\end{tabular}


Table 2. Participating laboratories and instrumentation used in the interlaboratory study

\begin{tabular}{|c|c|c|c|}
\hline \multirow{2}{*}{ Laboratory } & \multicolumn{3}{|c|}{ Instrumentation } \\
\hline & Weathering & Soiling & Measurements \\
\hline$A$ & $\begin{array}{l}\text { Weathering } \\
\text { Tester (Q- } \\
\text { Lab QUV) }\end{array}$ & $\begin{array}{l}\text { Stainless steel air-pressurized tank } \\
\text { (Alloy Products Corp. B501-0865-00) } \\
\text { with hollow-cone fine spray nozzle } \\
\text { (Spraying Systems Co. UniJet } 1 / 4 \text { TT- } \\
\text { SS+SS-CO-SF2) }\end{array}$ & $\begin{array}{c}\text { Solar Spectrum Reflectometer } \\
\text { (Devices \& Services model SSR-E, } \\
\text { version 5) }\end{array}$ \\
\hline B & same & $\begin{array}{l}\text { Air-pressurized vessel with hollow- } \\
\text { cone fine spray nozzle spray }\end{array}$ & $\begin{array}{c}\text { Solar Spectrum Reflectometer } \\
\text { (Devices \& Services model SSR-E, } \\
\text { version v6) } \\
\text { Emissometer (Devices \& Services } \\
\text { model RD1 AE1) }\end{array}$ \\
\hline C & same & $\begin{array}{l}\text { Air-pressurized vessel with hollow- } \\
\text { cone fine spray nozzle spray }\end{array}$ & $\begin{array}{c}\text { Solar Spectrum Reflectometer } \\
\text { (Devices \& Services model SSR-E, } \\
\text { version 6) } \\
\text { Emissometer (Devices \& Services } \\
\text { model RD1 AE1) }\end{array}$ \\
\hline $\mathrm{D}$ & same & $\begin{array}{l}\text { Air-pressurized vessel (74-01 } \\
\text { stainless steel model from Alloy } \\
\text { products Co.) with hollow-cone fine } \\
\text { spray nozzle (Spraying System Co.) }\end{array}$ & $\begin{array}{c}\text { UV-Vis-NIR Spectrophotometer } \\
\text { (JASCO model V-670 with } 150 \mathrm{~mm} \\
\text { ILN-725 integrating sphere) } \\
\text { Emissometer (Devices \& Services } \\
\text { model RD1 AE1, with model AE- } \\
\text { ADP port adapter) }\end{array}$ \\
\hline$E$ & same & $\begin{array}{l}\text { Air-pressurized vessel with hollow- } \\
\text { cone fine spray nozzle spray }\end{array}$ & $\begin{array}{c}\text { Solar Spectrum Reflectometer } \\
\text { (Devices \& Services model SSR-E, } \\
\text { version 6) } \\
\text { Emissometer (Devices \& Services } \\
\text { model RD1 AE1) }\end{array}$ \\
\hline $\mathrm{F}$ & same & $\begin{array}{l}\text { Air-pressurized vessel \& hollow-cone } \\
\text { fine spray nozzle spray }\end{array}$ & $\begin{array}{c}\text { Solar Spectrum Reflectometer } \\
\text { (Devices \& Services model SSR-E, } \\
\text { version 6) } \\
\text { Emissometer (Devices \& Services } \\
\text { model RD1 AE1) }\end{array}$ \\
\hline $\mathrm{G}$ & same & $\begin{array}{l}\text { Air-pressurized vessel \& hollow-cone } \\
\text { fine spray nozzle spray }\end{array}$ & $\begin{array}{c}\text { UV-Vis-NIR Spectrophotometer } \\
\text { (Perkin Elmer Lambda 950 with } \\
\text { Labsphere } 150 \mathrm{~mm} \text { integrating } \\
\text { sphere) } \\
\text { Emissometer (Devices \& Services } \\
\text { model RD1 AE1) }\end{array}$ \\
\hline $\mathrm{H}$ & same & $\begin{array}{l}\text { Air-pressurized vessel \& hollow-cone } \\
\text { fine spray nozzle spray }\end{array}$ & $\begin{array}{c}\text { Solar Spectrum Reflectometer } \\
\text { (Devices \& Services model SSR-E, } \\
\text { version 6) }\end{array}$ \\
\hline 1 & same & Q-Lab Q-SUN XE-3 & $\begin{array}{c}\text { UV-Vis-NIR Spectrophotometer } \\
\text { (Agilent Varian Cary model 6000i } \\
\text { with diffuse reflectance accessory } \\
\text { Varian model DRA-1800) }\end{array}$ \\
\hline
\end{tabular}


Table 3. Precision statistics for aged solar reflectance of 12 roofing products

\begin{tabular}{|c|c|c|c|c|c|c|}
\hline Product \# & Roofing category & $\overline{\bar{x}}$ & $s_{r}$ & $s_{R}$ & $r(\hat{r})$ & $\boldsymbol{R}(\widehat{R})$ \\
\hline 1 & factory applied coating & 0.661 & 0.008 & 0.022 & $0.022(3.3 \%)$ & $0.061 \quad(9.2 \%)$ \\
\hline 2 & single-ply membrane & 0.638 & 0.010 & 0.028 & $0.024(3.8 \%)$ & $0.074(11.7 \%)$ \\
\hline 3 & asphalt shingle & 0.262 & 0.007 & 0.015 & $0.021(7.9 \%)$ & $0.042(15.9 \%)$ \\
\hline 4 & clay tile & 0.342 & 0.007 & 0.024 & $0.020(5.8 \%)$ & $0.067(19.6 \%)$ \\
\hline 5 & modified bitumen & 0.625 & 0.012 & 0.030 & $0.034(5.4 \%)$ & $0.082(13.1 \%)$ \\
\hline 6 & concrete tile & 0.738 & 0.009 & 0.024 & $0.026(3.5 \%)$ & $0.067 \quad(9.1 \%)$ \\
\hline 7 & field applied coating & 0.748 & 0.015 & 0.036 & $0.040(5.4 \%)$ & $0.098(13.1 \%)$ \\
\hline 8 & bare zincalume steel & 0.629 & 0.006 & 0.032 & $0.018(2.8 \%)$ & $0.088(14.0 \%)$ \\
\hline 9 & field applied coating & 0.715 & 0.019 & 0.032 & $0.053(7.4 \%)$ & $0.088(12.3 \%)$ \\
\hline 10 & single-ply membrane & 0.665 & 0.015 & 0.025 & $0.043(6.4 \%)$ & $0.069(10.4 \%)$ \\
\hline 11 & single-ply membrane & 0.660 & 0.015 & 0.032 & $0.042(6.3 \%)$ & $0.088(13.4 \%)$ \\
\hline 12 & modified bitumen & 0.683 & 0.015 & 0.030 & $0.040(5.9 \%)$ & $0.083(12.1 \%)$ \\
\hline
\end{tabular}


Table 4. Precision statistics for aged thermal emittance of 12 roofing products

\begin{tabular}{|c|c|c|c|c|c|c|}
\hline Product \# & Roofing category & $\overline{\bar{x}}$ & $s_{r}$ & $s_{R}$ & $r(\hat{r})$ & $\boldsymbol{R}(\widehat{\boldsymbol{R}})$ \\
\hline 1 & factory applied coating & 0.848 & 0.011 & 0.021 & $0.030(3.5 \%)$ & $0.058(6.8 \%)$ \\
\hline 2 & single-ply membrane & 0.883 & 0.008 & 0.015 & $0.022(2.5 \%)$ & $0.042(4.8 \%)$ \\
\hline 3 & asphalt shingle & 0.897 & 0.012 & 0.021 & $0.032(3.6 \%)$ & $0.057 \quad(6.4 \%)$ \\
\hline 4 & clay tile & 0.846 & 0.011 & 0.012 & $0.030(3.5 \%)$ & $0.034 \quad(4.0 \%)$ \\
\hline 5 & modified bitumen & 0.875 & 0.018 & 0.018 & $0.050(5.8 \%)$ & $0.049(5.6 \%)$ \\
\hline 6 & concrete tile & 0.891 & 0.021 & 0.050 & $0.059(6.6 \%)$ & $0.139(15.6 \%)$ \\
\hline 7 & field applied coating & 0.880 & 0.008 & 0.011 & $0.021(2.4 \%)$ & $0.030(3.5 \%)$ \\
\hline 8 & bare zincalume steel & 0.326 & 0.009 & 0.013 & $0.024(7.3 \%)$ & $0.036(11.0 \%)$ \\
\hline 9 & field applied coating & 0.881 & 0.010 & 0.013 & $0.027(3.1 \%)$ & $0.037 \quad(4.2 \%)$ \\
\hline 10 & single-ply membrane & 0.887 & 0.006 & 0.014 & $0.017(1.9 \%)$ & $0.038 \quad(4.2 \%)$ \\
\hline 11 & single-ply membrane & 0.870 & 0.010 & 0.022 & $0.028(3.3 \%)$ & $0.061 \quad(7.0 \%)$ \\
\hline 12 & modified bitumen & 0.886 & 0.016 & 0.016 & $0.044(5.0 \%)$ & $0.045(5.1 \%)$ \\
\hline
\end{tabular}




\section{Figure Captions}

Figure 1. Within-laboratory consistency statistic $(k)$ of aged solar reflectance for 12 roofing products (a) tested by nine participants (Labs A-I); and (b) tested by eight participants (Labs A$H$ ). Off-scale $k$ statistics for products 2 and 3 calculated for lab I (8.77 and 4.78, respectively) are not shown in subfigure a.

Figure 2. Between-laboratory consistency statistic $(h)$ of aged solar reflectance for 12 roofing products tested by (a) nine participating laboratories (Labs A-I); and (b) eight participating laboratories (Labs A-H).

Figure 3. Within-laboratory consistency statistic $(k)$ of aged thermal emittance for 12 roofing products tested by Laboratories B-G.

Figure 4. Between-laboratory consistency statistic $(h)$ of aged thermal emittance for 12 roofing products tested Laboratories B-G.

Figure 5. Standard deviations of repeatability $\left(s_{r}\right)$ and reproducibility $\left(s_{R}\right)$ v.s. average measured aged solar reflectance, shown for the 12 roofing products tested.

Figure 6. Standard deviations of repeatability $\left(s_{r}\right)$ and reproducibility $\left(s_{R}\right)$ vs. average measured aged thermal emittance, shown for the 12 roofing products tested. 


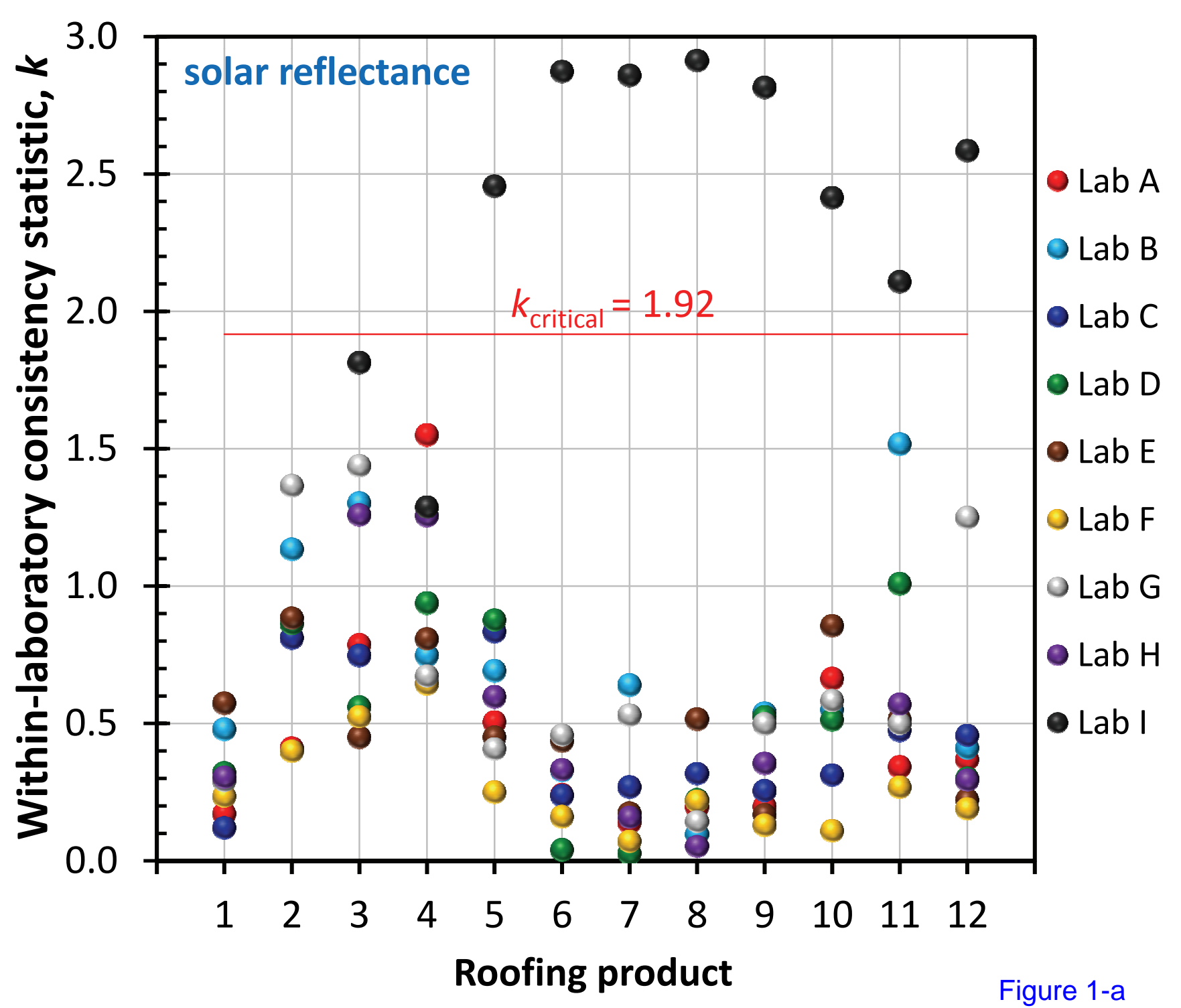




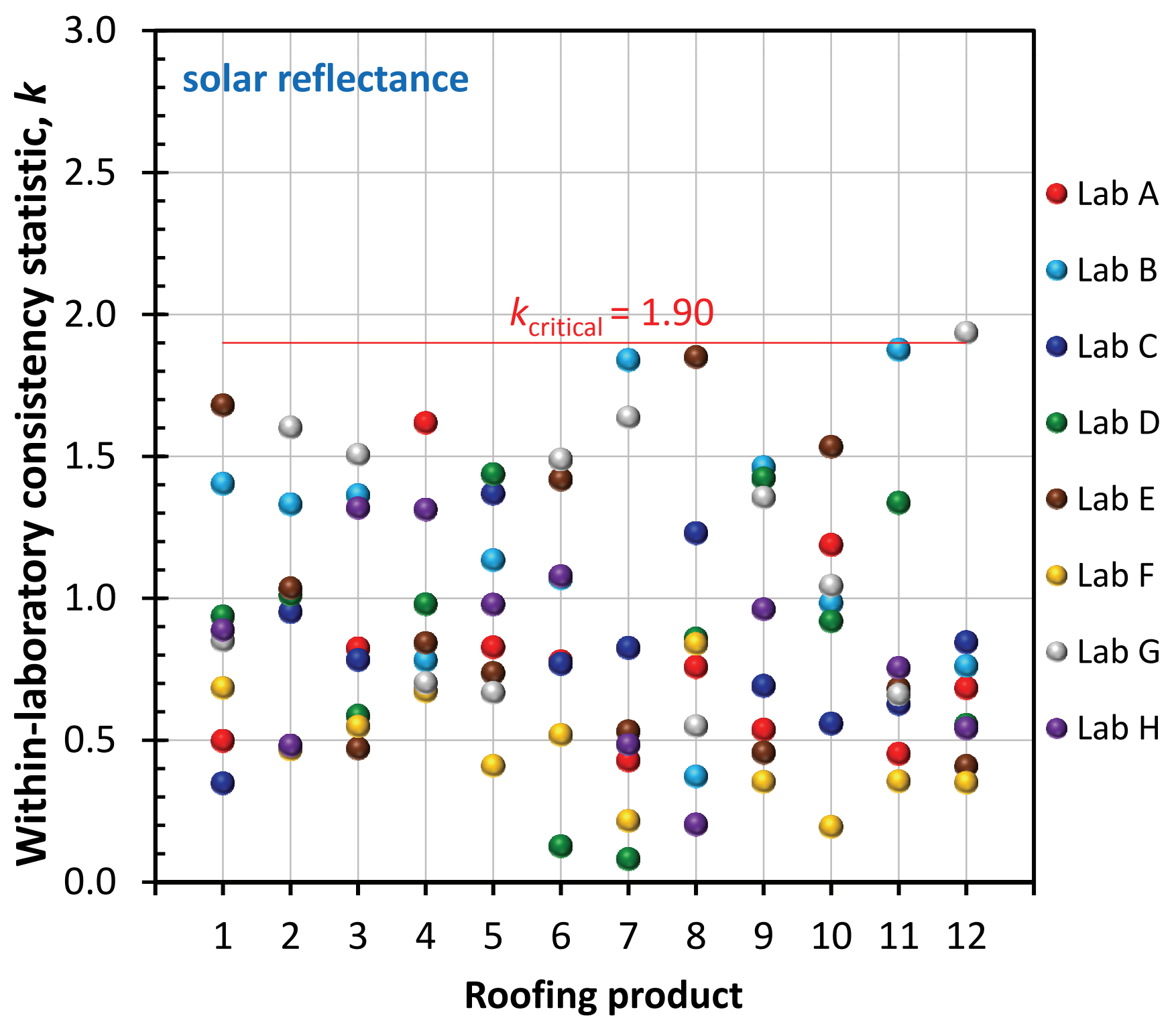

Figure 1-b 


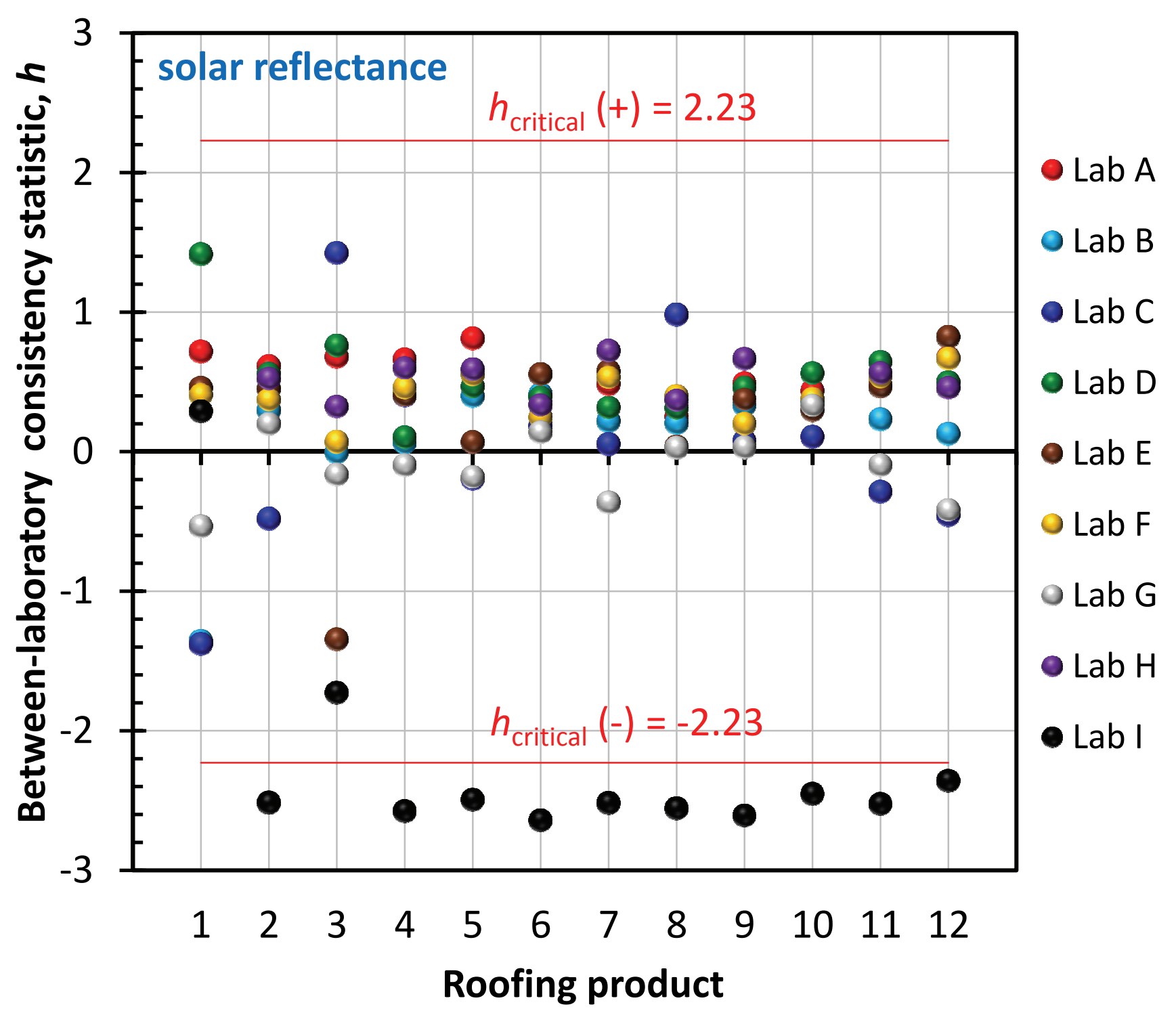

Figure 2-a 


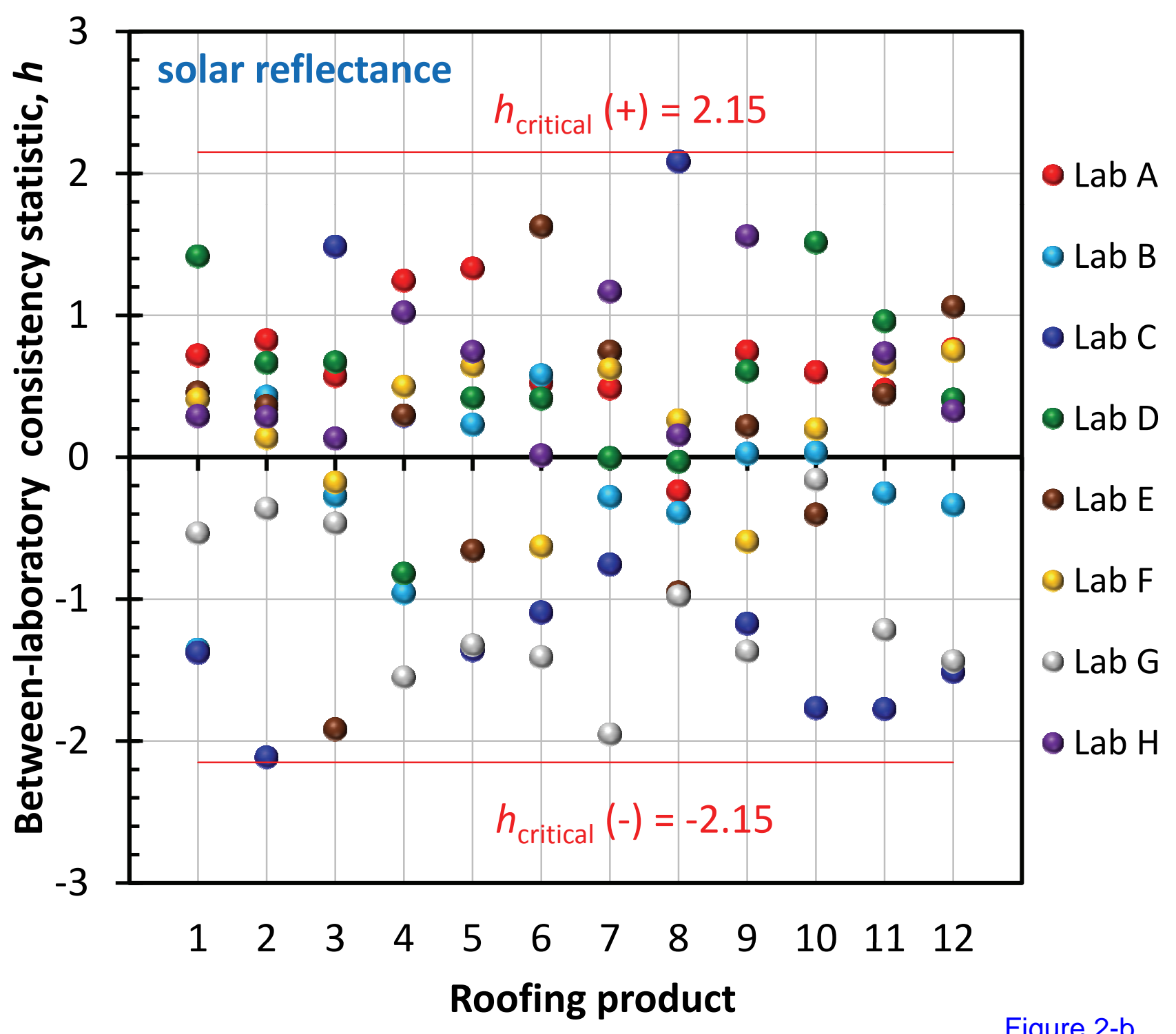

Figure 2-b 


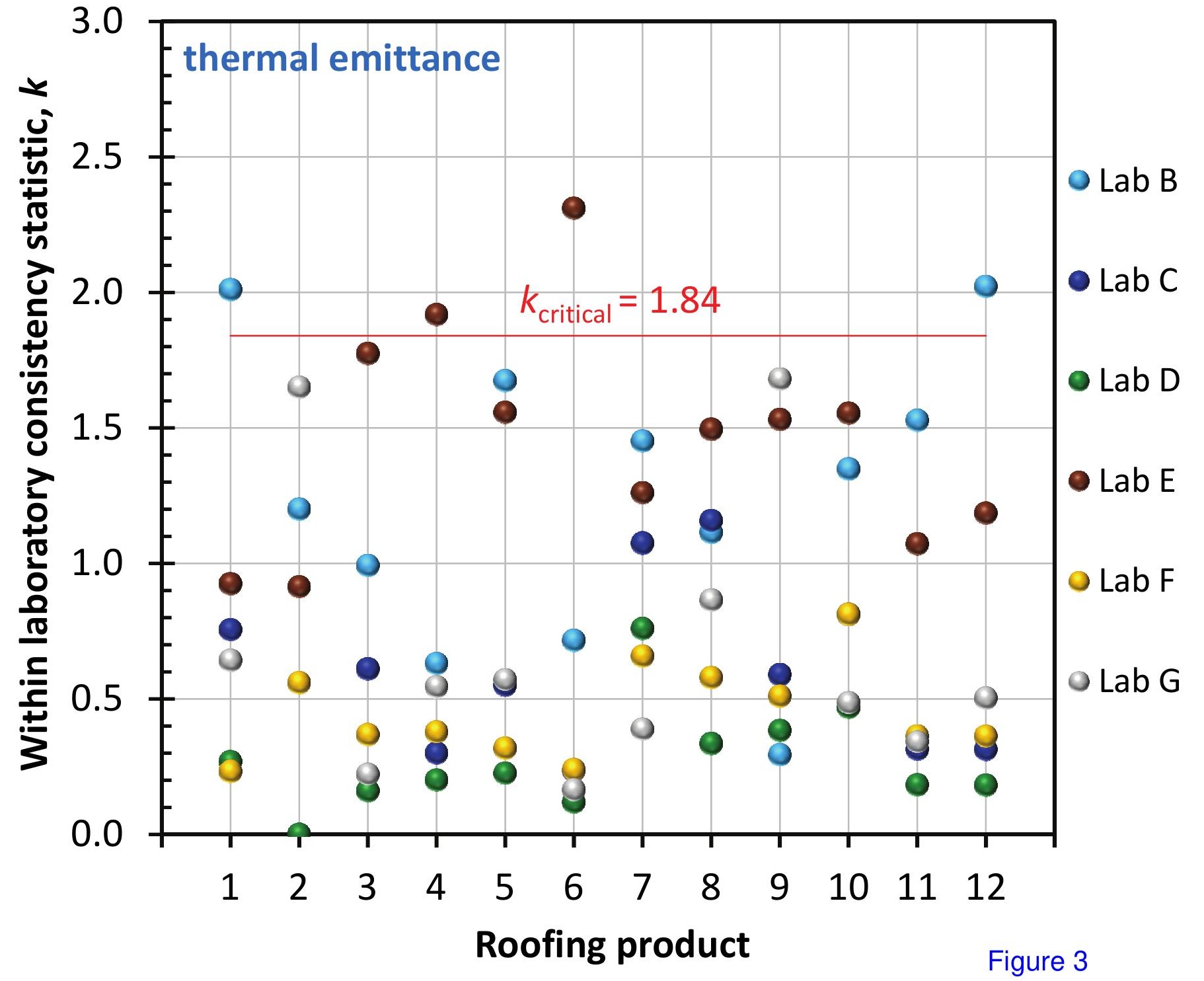




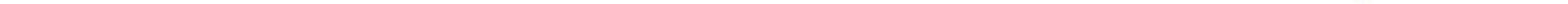




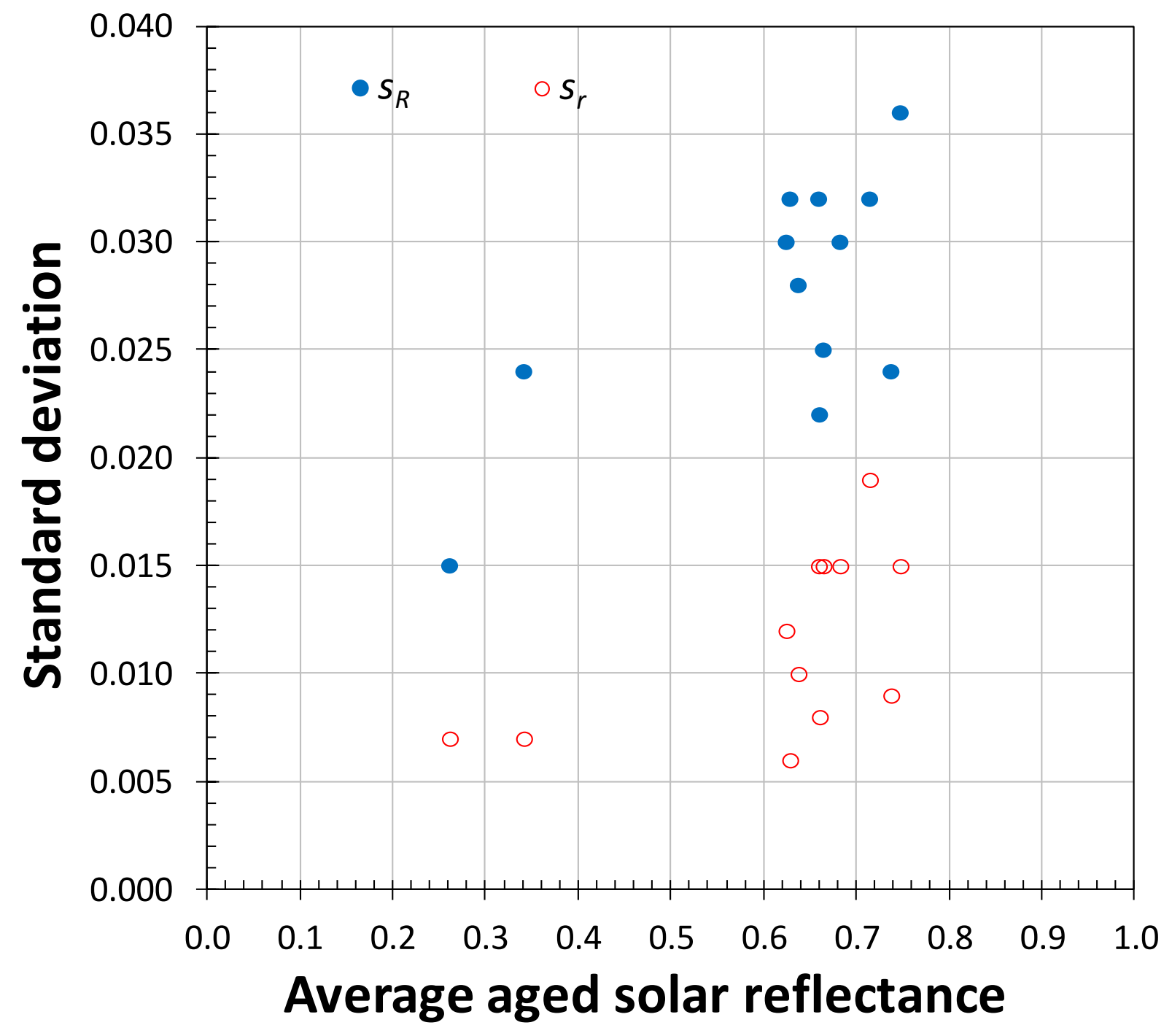

Figure 5 


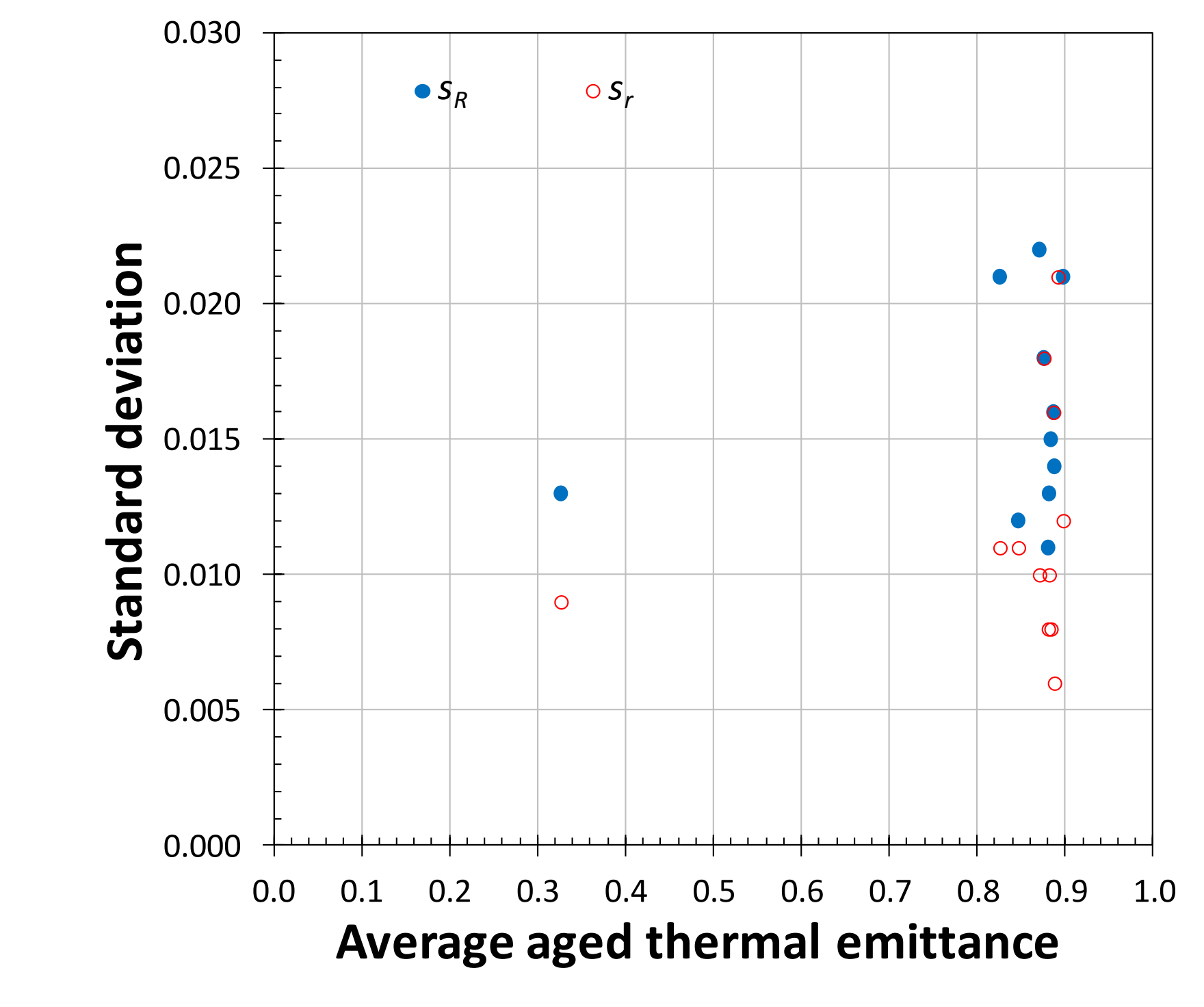

Figure 6

Figure 6

.
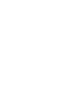

(n)

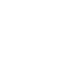

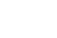

6

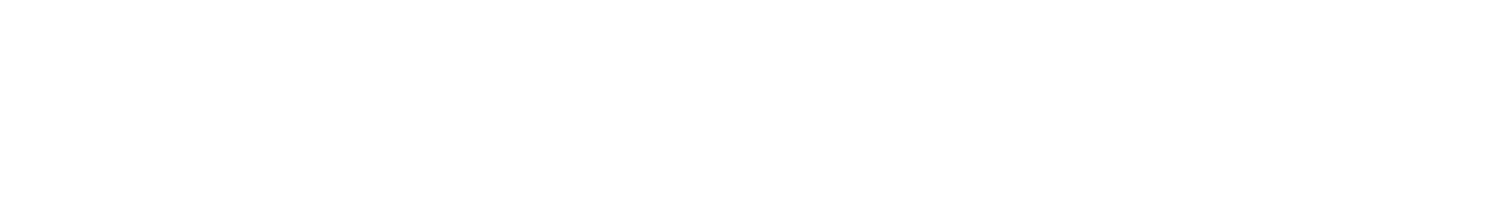

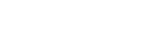

